\title{
Tuberculosis of Thyroid Gland: A Case Report with Review of Articles
}

\section{Sanjay Sengupta, Subrata Pal, Jyoti Prakash Phukan, Kingshuk Bose, Sritanu Jana}

Department of Pathology, Bankura Sammilani Medical College, Bankura, India. Email: subratapal1985@gmail.com

Received December $26^{\text {th }}, 2012$; revised April $2^{\text {nd }}, 2013$; accepted June $19^{\text {th }}, 2013$

Copyright (C) 2013 Sanjay Sengupta et al. This is an open access article distributed under the Creative Commons Attribution License, which permits unrestricted use, distribution, and reproduction in any medium, provided the original work is properly cited.

\begin{abstract}
Objective: Tuberculosis of thyroid gland is encountered in only $0.1 \%-0.4 \%$ thyroid biopsies. We are presenting a case to emphasize inclusion of this rare disorder as a potential differential diagnosis during the assessment of thyroid lesions. Case report: 38-year female presented with a cystic nodule of left lobe of thyroid. Guided aspiration yielded only necrosed material. Biopsy revealed caseating granuloma with giant cells. Tuberculosis etiology was confirmed by PCR examination. Conclusion: Thyroid tuberculosis should always be considered as a probability during assessment of any midline cervical mass. Pre-operative diagnosis can avoid unnecessary surgery.
\end{abstract}

Keywords: Tuberculosis; Thyroid Gland

\section{Introduction}

Tuberculous thyroiditis is infrequently reported even from endemic areas [1,2]. Before demonstration of glandular involvement in a case of disseminated tuberculosis by Lebert (1862), thyroid gland was considered immune from the disease [3]. Bruns (1893) reported similar involvement without any evidence of military or pulmonary tuberculosis [4]. Still today few cases are documented world wide $[1,5,6]$.

Incidence of thyroid tuberculosis varies from $0.1 \%$ $0.4 \%[1,6,7]$. Possible attributable factors for relative resistance to infection can be intact thyroid capsule; rich vascular and lymphatic supply; high iodine content of the gland; bactericidal activity of colloid and thyroid hormones; enhanced phagocytic activity of gland macrophages as seen during hyperthyroidism [1,2].

Primary involvement of the thyroid gland can only be explained as reactivation of the latent focus of infection [4]. But secondary involvement can be haematogenous or lymphatic from distant sites (lung) or directly from local sites (larynx, lymph nodes), particularly occurring during progressive infection $[1,4]$.

\section{Case Report}

38-year female presented with a smooth firm, globular swelling $(3.5 \times 3 \times 2) \mathrm{cm}^{3}$ of left lobe of thyroid, gradually increasing since one year without lymphadenopathy or dyshormonogenesis. Ultrasonography demonstrated a cystic swelling $(2.8 \times 2.3 \times 1.6) \mathrm{cm}^{3}$. Subsequent biopsy revealed follicular destruction with caseating epithelioid granuloma containing Langhan's type giant cells (Figure 1). Acid fast bacilli could not be demonstrated in Zheel Neelsion stained sections. Routine haematology and chest radiograph findings were within normal limit. Tuberculosis etiology was confirmed by polymerase chain reaction (PCR) of thyroid tissue sample.

\section{Discussion}

Few organs in our body are relatively resistant to tuberculosis like heart, striated muscles, pancreas, prostate, cervix and thyroid gland [1]. Rokitasky and Dasetal in there large series of thyroid biopsies and aspiration, respectively, reported $0.1 \%$ and $0.6 \%$ tuberculous lesion $[5,8,9]$. Because of rarity thyroid tuberculosis is seldom reported clinically $[5,8,9]$.

Clinical presentation of tuberculous thyroiditis is highly variable. Majority are middle aged women with a solitary, slow growing nodule and an euthyroid status, similar to the present case $[5,6]$. Other features uncommonly encountered are-dysphonia, dysphagia or dyspnoea; thyrotoxicosis, or hypothyroidism; subacute thyoiditis; thyroid abscess; rapid enlargement with adherence mimicking cancer $[1,5,6]$.

Tuberculosis of thyroid may present with following 


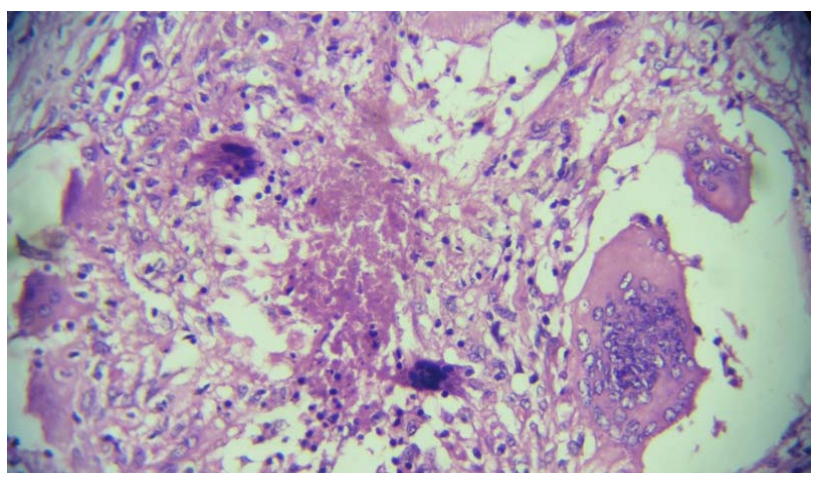

Figure 1. Caseous necrosis and Langhan's giant cell (H \& E stain, $40 \times$ ).

morphological changes: multiple minute lesions mimicking miliary involvement; glandular enlargement due to caseating granuloma; cold abscess and sinus formation; chronic fibrosing tuberculosis simulating De Quervein's thyroiditis; rapid enlargement mimicking carcinoma due to acute abscess formation $[1,8,9]$. So, gross examination of excised gland often fails to confirm etiology [2].

Microscopically four variants of tuberculous thyroiditis have been documented: multiple minute tubercles of miliary disease, solitary or merging tubercles, foci of caseous necrosis or cold abscess and cicatrised tubercle foci [1]. Characteristic microscopic feature is destruction of thyroid follicle by necrotizing epithelioid granuloma containing giant cells [1,5]. It can be differentiated from other granulomatous diseases of thyroid (sarcoidosis, granulomatous thyroiditis, fungal granuloma, granulomatous vasculitis or foreign body granuloma) by caseative necrosis and presence of langhan's type giant cells [9]. However, demonstration of acid fast bacilli from sections or culture should always be attempted, though often without success, as experienced by us [1,5].

Seed proposed three criteria for diagnosis of thyroid tuberculosis: 1) Demonstration of acid fast bacilli within thyroid; 2) A necrotic or abscessed gland; 3) Demonstration of tuberculous focus outside. The third criterion is not essential for confirmed diagnosis [1,4]. Even bacteriological confirmation is not always achievable and characteristic histological finding reported from an endemic area is accepted as confirmatory [4]. In these cases polymerase chain reaction can be a reliable method to prove presence of Mycobacterium tuberculosis within thyroid, as utilized in the present case [7].

Fine needle aspiration cytology can also confirm thyroid involvement by demonstration of epithelioid granuloma, necrosis and Langhan's type giant cells. But majority of the thyroid aspirates yield only necrotic material, as experienced by us [5,7]. Successful attempts to demonstrate acid fast bacilli from necrosed material directly or after culture have been documented [7]. We missed this opportunity because of the lack of suspicion. Correct cytodiagnosis reduces unnecessary surgery as patients can be managed medically $[1,5,7]$.

\section{Conclusion}

We are presenting a rare case of thyroid tuberculosis as confirmed after histopathological examination. Despite rarity tuberculosis should always be considered as a possible diagnosis during the evaluation of thyroid biopsies. FNAC should be considered as the best option for diagnosis and pus or necrosed material aspirated from the thyroid must be subjected to appropriate microbiological examinations.

\section{REFERENCES}

[1] S. P. Kataria, P. Tanwar, S. Singh and S. Kuma, "Primary Tuberculosis of Thyroid Gland: A Case Report,” Ascian PJ of Tropical Biomedicine, Vol. 2, No. 10, 2012, pp. 839-840.

[2] V. Zivaljevic, I. Paunovic and A. Diklik, "Tuberculosis of Thyroid Gland: A Case Report,” Acta Chirurgica Belgica, Vol. 107, No. 1, 2007, pp. 70-72.

[3] N. A. Khan, A. R. Patgaroo, S. W. Murtaza, S. Kotal, P. Singh and N. D. Chowdhery, "Isolated Tuberculosis of Thyroid Gland,” JK Science, Vol. 4, No. 2, 2002, pp. 8788.

[4] D. Balasarkar, M. A. Joshi, J. Dhareswar, R. R. Satoskar, N. Awsare, R. Mahey and V. Kumar, "Primary Thyroid Tuberculosis,” Bombay Hospital Journal, Vol. 41, No. 2, 1999.

[5] A. Fareed, A. Sameer and A. A Mallik, "Primary TuberCulosis of Thyroid Gland,” The Kuwait Medical Journal, Vol. 37, No. 2, 2005, pp. 116-118.

[6] A. B. Sharma, L. D. Kumar, H. D. Sharma, K. Sharma and S. Naorem, "Primary Tuberculosis of Thyroid Gland-A Rarity,” JIACM, Vol. 7, No. 4, 2006, pp. 363-364.

[7] P. C. Modayil, A. Leslie and A. Jacob, "Tuberculous Infection of Thyroid Gland: A Case Report,” Case Reports in Medicine, Vol. 2009, 2009, Article ID: 416231. doi:10.1155/2009/416231

[8] A. A. Pandit, A. S. Joshi, S. B. Ogale and J. H. Sheode, "Tuberculosis of Thyroid Gland," Indian Journal of Tuberculosis, Vol. 44, 1997, pp. 205-207.

[9] D. K. Das, C. S. Pant, K. L. Chachra and A. K. Gupta, "Fine Needle Aspiration Cytology of Tuberculous Thyroiditis. A Report of Eight Cases,” Acta Cytologica, Vol. 36, No. 4, 1992, pp. 517-522. 